\title{
Taxonomy of the poorly known Quedius mutilatus group of wingless montane species from Middle Asia (Coleoptera: Staphylinidae: Staphylinini)
}

\author{
Maria SALNITSKA ${ }^{1} \&$ Alexey SOLODOVNIKOV ${ }^{2, *}$ \\ ${ }^{1}$ Department of Entomology, St. Petersburg State University, Universitetskaya Embankment 7 / 9, \\ Saint-Petersburg, Russia. \\ ${ }^{2}$ Natural History Museum of Denmark, Universitetsparken 15, Copenhagen 2100, Denmark. \\ ${ }^{1}$ Email: m.salnitska@gmail.com \\ ${ }^{2}$ Corresponding author: asolodovnikov@snm.ku.dk \\ ${ }^{1}$ urn:1sid:zoobank.org:author:5E4AABE4-42DE-4984-BE96-BAAAD698C387 \\ ${ }^{2}$ urn:lsid:zoobank.org:author:E56B0FF6-38F5-48D7-A5C1-0EA071EB4A99
}

\begin{abstract}
The Quedius mutilatus group, a very poorly known presumably monophyletic complex of wingless, possibly hypogean species confined to the Tien-Shan Mountains, is characterized as such for the first time. Newly available material clarified the identity of Q. mutilatus Eppelsheim, 1888 and Q. kalabi Smetana, 1995, each hitherto known from a handful of non-conspecific and vaguely georeferenced specimens only. Additional material is reported for Q. equus Smetana, 2014 and one species, Quedius kungeicus sp. nov., is described. All available data on the taxonomy, distribution and bionomics for all these four species of the group are summarized.
\end{abstract}

Keywords. Rove beetles, new species, Microsaurus, allopatry, endemism.

Salnitska M. \& Solodovnikov A. 2018. Taxonomy of the poorly known Quedius mutilatus group of wingless montane species from Middle Asia (Coleoptera: Staphylinidae: Staphylinini). European Journal of Taxonomy 401: 1-17. https://doi.org/10.5852/ejt.2018.401

\section{Introduction}

The mega-diverse rove beetle genus Quedius Stephens, 1829 includes a small number of hypogean species with characteristic morphological modifications such as: notably reduced eyes, weaker cuticular pigmentation, dorso-ventrally flattened body with long legs, pronotum strongly narrowing anteriad, as well as reduced non-functional wings with corresponding shortened elytra and absence of a palisade fringe on the abdominal tergite VII. Hypogean species of Quedius are phylogenetically heterogeneous, while their distributions, bionomics and sister group relationships remain largely unexplored (Solodovnikov \& Hansen 2016). The poor systematic knowledge of these specialized Quedius is unfortunate, as the genus represents an interesting model to study speciation within the context of mountain orogenesis. In this respect, the similar species Q. mutilatus Eppelsheim, 1888, Q. kalabi Smetana, 1995 and Q. equus Smetana, 2014 (grouped here as the 'Q. mutilatus group') 
of the subgenus Microsaurus Dejean, 1833 seemed noteworthy, as they were the only members of the genus with such distinct morphological traits in the Tien-Shan, a vast mountain system of the Palaearctic region. As expected, the Q. mutilatus group was hitherto known from very scarce, mostly non-georeferenced material lacking bionomic data. Our examination of various collections of Quedius yielded new material that was collected over many decades and that sheds light on the composition, distribution and bionomics of this peculiar Asian species group. This paper reports these findings with, among other discoveries, a species new to science.

\section{Material and methods}

This paper is based on the examination of material from the following institutions and private collections:

$\mathrm{cRyv}=$ Private collection of A.B. Ryvkin, Moscow, Russia

$\mathrm{cSch}=$ Private collection of M. Schülke, Berlin, Germany (to be deposited at the Natural History Museum of Berlin)

NMW = Natural History Museum, Vienna, Austria (H. Schillhammer)

ZIN = Zoological Institute, Russian Academy of Sciences, St. Petersburg, Russia (B. Korotyaev)

ZMUC = Zoological Museum, University of Copenhagen (part of the Natural History Museum of Denmark), Copenhagen, Denmark (A. Solodovnikov, S. Selvantharan)

The holotype of the new species is deposited at ZIN.

Morphological examination and preparation of specimens were conducted using Lomo MSP-2 v. 2 and Leica M125 stereo microscopes. Measurements were recorded at $4.5 \times$ magnification using an ocular micrometer.

Abbreviations:

$\mathrm{EL}=$ length of elytra (from humerus to the most distal part of the posterior margin)

$\mathrm{EW}=$ width of elytra (maximum, with elytra closed along suture)

$\mathrm{FB}=$ forebody length

$\mathrm{HL}=$ head length (from base of labrum to neck constriction along the head midline)

$\mathrm{HW}=$ head width (maximum, including eyes)

$\mathrm{PL}=$ pronotum length (along midline)

$\mathrm{PW}=$ pronotum width (maximum)

Overall body length was measured from the apex of the labrum to the apex of the abdomen. All measurements are in $\mathrm{mm}$ unless otherwise indicated.

The photographs of the habitus and aedeagi were obtained with a Nikon D700 digital SLR camera attached to a Nikon SMZ 1500 stereo microscope. Photos and line drawings of the male genitalia are based on preparations of their soft parts in glycerin (obtained via dissecting, maceration in 10\% $\mathrm{KOH}$ and rinsing in distilled water). Pencil sketches for subsequent computer-based inking were made using a drawing tube attached to a Nikon SMZ 1500 binocular microscope.

The species distribution map in Fig. 1 was produced with QGIS 2.12.0 free software. It is based on the approximate geographic coordinates that we were able to find with the aid of various printed maps or online systems (Google Maps, Google Earth and others) for the toponyms indicated on the specimen labels. Our friend and colleague Ilya Kabak (St. Petersburg, Russia) kindly communicated the coordinates for the specimens he collected. Since none of the geographic coordinates are indicated on the original locality labels for any of the examined specimens, they are given in square brackets in the 'Material examined' sections. Specimen labels with very ambiguously indicated localities are cited verbatim and given between quotation marks. All our interpretations of such labels are given in square brackets. 


\section{Results}

Family Staphylinidae Latreille, 1802

Subfamily Staphylininae Latreille, 1802

Tribe Staphylinini Latreille, 1802

Subtribe Quediina Kraatz, 1857

Genus Quedius Stephens, 1829

Subgenus Microsaurus Dejean, 1833

\section{Quedius mutilatus group}

\section{Diagnosis}

The Quedius mutilatus group of species can be recognized as follows: relatively large Microsaurus (body length $8-11.6 \mathrm{~mm}$ ) with brown to dark brown, dorso-ventrally flattened body, with notably small eyes and pronounced signs of brachyptery such as short elytra and absent palisade fringe on abdominal tergite VII; head with posterior frontal puncture situated very close to neck; pronotum with distinct anterior and posterior angles, normally with three punctures in dorsal rows with anteriormost (smaller) puncture located latero-anteriorly at pronotal anterior margin, and with one to two sublateral punctures situated slightly anterior to large lateral puncture; scutellum impunctate; aedeagus robust, symmetrical, with apical portion of median lobe slightly curved towards paramere, with characteristic tooth near apex (in lateral view), with paramere widest shortly before apex (in parameral view) and with four distinct groups of sensory peg setae: two apical and two lateral.

\section{List of species}

Quedius mutilatus Eppelsheim, 1888; Quedius kalabi Smetana, 1995; Quedius equus Smetana, 2014 and Quedius kungeicus sp. nov.; all species can be reliably separated from each other by the structure of the aedeagus only.

\section{Distribution}

All species of the group seem to be allopatric (Fig. 1): Quedius mutilatus Eppelsheim, 1888 is restricted to the central part of Terskei Alatau, south of Issyk-Kul Lake; it is replaced eastwardly by $Q$. kalabi Smetana, 1995 and then Q. equus Smetana, 2014, the latter probably being distributed throughout NE Terskei Alatau to Xinjiang Province in China. Quedius kungeicus sp. nov. is known from the type locality in eastern Kungei Alatau only. There is a single female from the high altitudes of Atbashi Mountain in Central Tien-Shan, which presumably belongs to the $Q$. mutilatus group, but cannot be further identified without associated males. Three ambiguous specimens from Toksanbai in Dzungarian Alatau, damaged by dermestids, are presumably mislabelled and in fact originate from Terskei Alatau, because a single fully preserved male among them displays an aedeagus of the $Q$. kalabi type. All specimens of the $Q$. mutilatus group with recorded bionomic data indicate a specialization to high elevations.

\section{Systematics}

Some authors affiliated Q. mutilatus with Q. przewalskii Reitter, 1887 (Reitter 1887; Boháč 1988) or with the Q. przewalskii group (Smetana 2014); the latter, however, lacks a clear definition (Solodovnikov \& Hansen 2016). For example, Smetana (2014) affiliated Q. mutilatus and Q. equus to the Q. przewalskii group, contrary to his (e.g., Smetana 2001) earlier opinion of the composition of this group. Based on body chaetotaxy and the shape of the aedeagus, it could be related to $Q$. puncticollis (Thomson, 1867), as proposed by Coiffait (1978). The Q. puncticollis group of Coiffait (1978) is phylogenetically heterogeneous, based on the diverse morphology and scattered distributions of species. We establish the Q. mutilatus group here for Q. mutilatus and related species from Tien-Shan. Members of the group 
markedly differ from $Q$. puncticollis and related species in a microphthalmous, brachypterous habitus, with weakly pigmented coloration and in the shape of the aedeagus, with a pointed apex of the median lobe and sensory peg setae arranged in apical and lateral groups. The Q. mutilatus group differs from the Q. przewalskii group, in the more restricted sense of Smetana (2001), in having three (contrary to one or two) punctures in the dorsal rows of the pronotum and in the structure of the aedeagus, which is symmetrical, with a median lobe having a pointed apex and a more basally positioned ventral tooth, and with wide parameres having two groups of sensory peg setae (apical and lateral).

All species of this group are individually treated below. In addition to the description of a new species, a redescription is provided for $Q$. mutilatus, the most commonly cited species of the group with which other, later described species have been compared.

\section{Quedius mutilatus Eppelsheim, 1888}

Figs 1-2, 4A-B

Quedius mutilatus Eppelsheim, 1888: 58 (original description).

Quedius mutilatus - Gridelli 1924: 23 (redescription). — Coiffait 1978: 161 (redescription). — Smetana 1998: 118 (lectotype designation, illustrations, comparison with Q. kalabi).

\section{Material examined}

Type material

KYRGYZSTAN: Terskei Alatau mountain range, lectotype, $\hat{\partial}, “ \hat{\partial} / 245$ [handwritten label]/Fluss. Tamgi [river Tamga in Karakol Gorge] Turkestan. Leg. Akinin [handwritten label]/c.Epplsh. Steind. d [printed label]/Q. mutilatus Epp. Type [handwritten label]/TYPUS [red printed label]/LECTOTYPE Quedius mutilatus Eppelsheim A. Smetana des. 1997 [red handwritten label]" (NMW).

\section{Additional material}

KYRGYZSTAN: Terskei Alatau mountain range: $2 \stackrel{\partial}{\text { }}$, Barskoon Valley [42.0900 $\left.{ }^{\circ} \mathrm{N}, 77.5900^{\circ} \mathrm{E}\right]$,

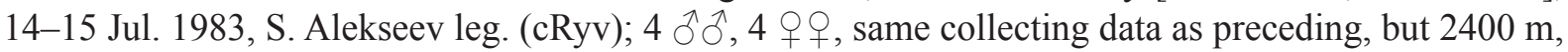

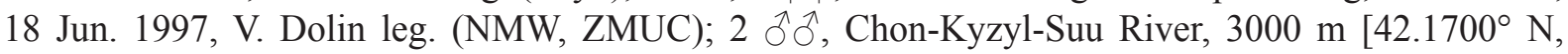

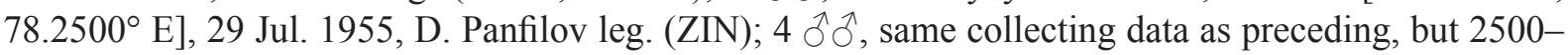

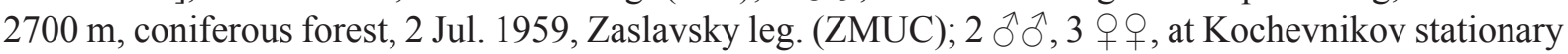
( $25 \mathrm{~km}$ S of village Pokrovka [village Kyzyl-Suu]), $2450 \mathrm{~m}\left[42.1260^{\circ} \mathrm{N}, 78.0250^{\circ} \mathrm{E}\right.$ ], coniferous forest, leaf litter under moss and grass, 2-7 Jul. 1988, V. Yanushev leg. (cRyv); 4 ôे, 2 o 9 , same collecting data as preceding, but 27-28 Jun. 1988 (cRyv); $2 \hat{\jmath}, 4$ 우, same collecting data as preceding, but coniferous forest, 2500 m, 12-31 Aug. 1984, N. Turtseva leg. (cRyv, ZMUC); 1 ô, 4 우우, same collecting data as preceding, but 15-18 Jun. 1985 (cRyv); 2 우, same collecting data as preceding, but 19 Jun. 1986 (cRyv); 4 ठิ ô, 'Turkestan Akinin-Tepe' (NMW).

\section{Redescription}

Measurements and Ratios. Lectotype: HL: 1.07, HW: 1.11, PL: 1.30, PW: 1.52, EL: 1.16, EW: 1.57, FB: 3.52, HL/HW: 0.96, PL/PW: 0.85, EL/EW: 0.74; non-type material (range, arithmetic mean, $\mathrm{n}=$ 30): HL: 1.18-1.64 (1.36), HW: 1.11-1.57 (1.29), PL: 1.32-.82 (1.50), PW: 1.48-2.02 (1.74), EL: 1.251.70 (1.42), EW: 1.52-2.00 (1.70), FB: 3.77-5.07 (4.28), HL/HW: 0.93-1.22 (1.03), PL/PW: 0.79-0.95 (0.87), EL/EW: 0.75-0.93 (0.83).

BoDy. Length 8-12 $\mathrm{mm}$; brown to light brown including appendages, elytra and abdominal tergites, becoming slightly paler toward apex, sometimes head and abdomen slightly darker than pronotum and elytra; distinctly flattened dorso-ventrally. 
HEAD. About as long as wide [HL/HW: 0.93-1.22 (1.03)], with broadly arcuate posterior angles; surface with distinct microsculpture of transverse waves on disc, becoming more or less isodiametric on frons between eyes, and with distinct sparse non-setiferous micropunctation. Eyes small and flat, not protruding over lateral contour of head; temples about 2.00-3.18 (2.54) times as long as longitudinal diameter of eye. Head disc on each side with setiferous punctures as following: anterior frontal puncture at inner margin of eye, posterior frontal puncture very close to neck, and pair of smaller vertical punctures immediately medio-posteriorly from the latter puncture. Each temple with two temporal punctures of which posterior temporal puncture closer to posterior margin of head than to posterior margin of eye; additionally, temples with some fine setiferous punctures bearing short pale setae.

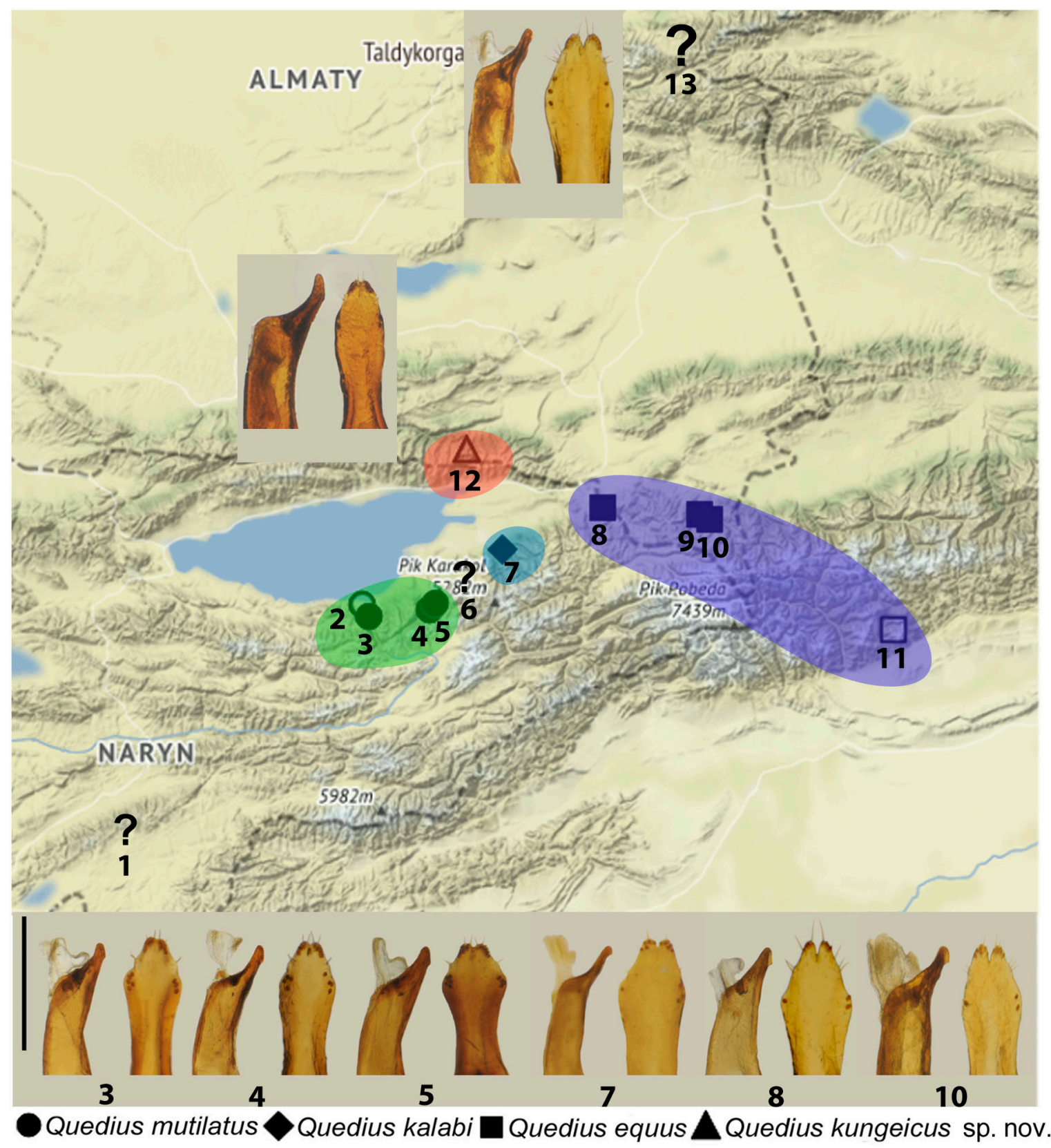

Fig. 1. Distribution and aedeagus variability of the Quedius mutilatus group in the Tien-Shan Mountains. Numbers are specified in Table 1. Empty symbols = type spcimens (for $Q$. kalabi precise locality of the holotype unknown); ? = ambiguously labelled or undetermined material. Scale bar: $0.5 \mathrm{~mm}$. 


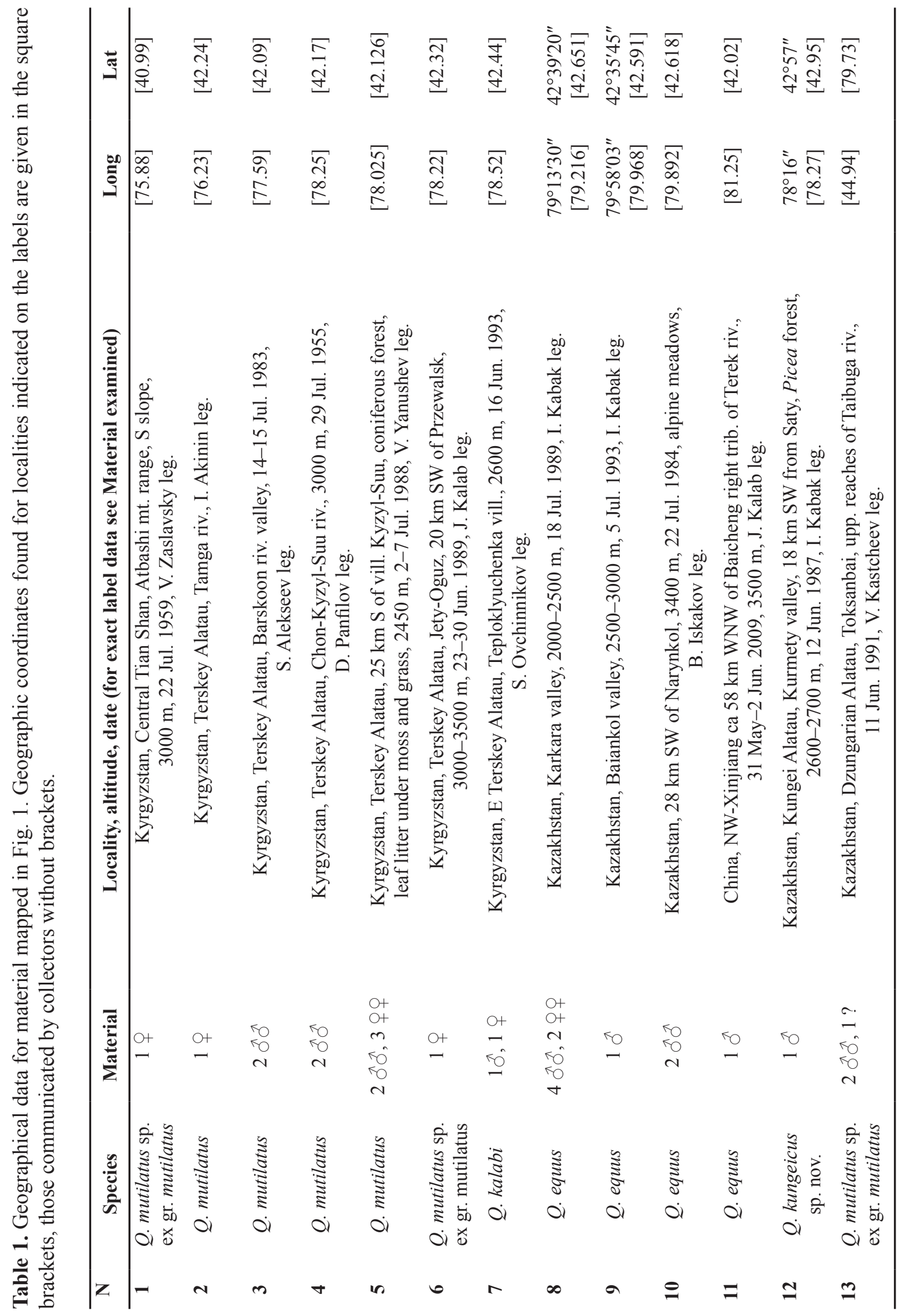


Antennae. Segments as following: second and third combined as long as first; third slightly longer than second; fourth and fifth, each, as long as wide; sixth to tenth, each, wider than long and gradually widening towards apex of antenna; last segment slightly shorter than two preceding segments combined.

Pronotum. Wider than long [PL/PW: 0.79- $0.95(0.86)]$ widest at about its middle, gradually narrowing anteriad and vaguely posteriad; anterior lateral portions sloping ventrad, posterior lateral portions slightly explanate; both anterior and posterior pronotal angles distinct; disc with microsculpture and non-setiferous micropunctation similar to that on posterior part of head. Disc with three setiferous punctures in each dorsal row: one puncture before middle of pronotum, one close to its anterior margin, and one (smaller) latero-anteriorly at pronotal anterior margin; sometimes some punctures weak or absent, in both or one row, or sometimes smaller additional puncture near basalmost discal puncture. Antero-lateral area of pronotal disc with one to two sublateral punctures situated slightly anterior to large lateral puncture.

Scutellum. Impunctate, with faint transverse microsculpture.

ELYTRA. Parallel-sided, relatively short [EL/EW: 0.74-1.12 (0.83)], about as long as pronotum [PL/EL: 0.98-1.20 (1.06)], and slightly narrower than pronotum at widest point [PW/EW: 0.94-1.34 (1.03)]; setiferous punctation fine and moderately dense with interspaces larger than punctures diameter, shiny, with distinct minute irregularities; pubescence yellowish to brownish. Wings vestigial.

AвDOMEN. With fine and dense punctation; interspaces with minute irregularities; posterior margin of tergite VII without palisade fringe (Fig. 2A).

\section{Male}

SeCONDARY SEXUAl characters. First three segments of front tarsus more strongly dilated than in females; second segment slightly wider or as wide as apex of tibia. Sternite VIII with distinct roughly triangular medio-apical emargination; tergite X triangular, strongly narrowed apically with few strong and numerous smaller apical setae; sternite IX moderately elongate with wide and glabrous basal, and sparsely setose and vaguely bilobed apical portion.

Aedeagus (Fig. 2B). Median lobe: (in parameral view) parallel-sided, with obtusely pointed apex; (in parameral or lateral view) with minute tooth situated near its apex. Paramere (in parameral view) as wide as median lobe, lanceolate, with slightly incised apex; underside with irregular groups of sensory peg setae, including a pair of apical groups with ca 3-7 peg setae in each group, and a pair of lateral groups with ca 4-6 peg setae each; additionally, parameral apex with normal setae including pair of apical setae on each side of apical incision and ca 1-4 lateral setae on each side below. Internal sac without large, strongly sclerotized structures.

\section{Female}

Secondary sexual characters. First four segments of protarsi dilated, but slightly narrower than in males. Tergite $\mathrm{X}$ triangular, gradually narrowed apically, pigmented and with long setae medioapically.

\section{Distribution and bionomics}

Quedius mutilatus is endemic to the central Terskei Alatau mountain range, where it is known from Karakol Gorge in the west (type locality) to the Chon-Kyzyl-Suu River in the east. Examined material has been collected from the second half of May through the end of August, all at high elevations around 2000-3000 m. At least some specimens without bionomic records were presumably found under stones as a by-catch by various entomologists, including specialists targeting Carabidae and Elateridae who, as a rule, intensively turn stones at elevations above the timber line. A few specimens with recorded bionomics have been found in coniferous leaf litter and other ground-based debris like grass or moss. 


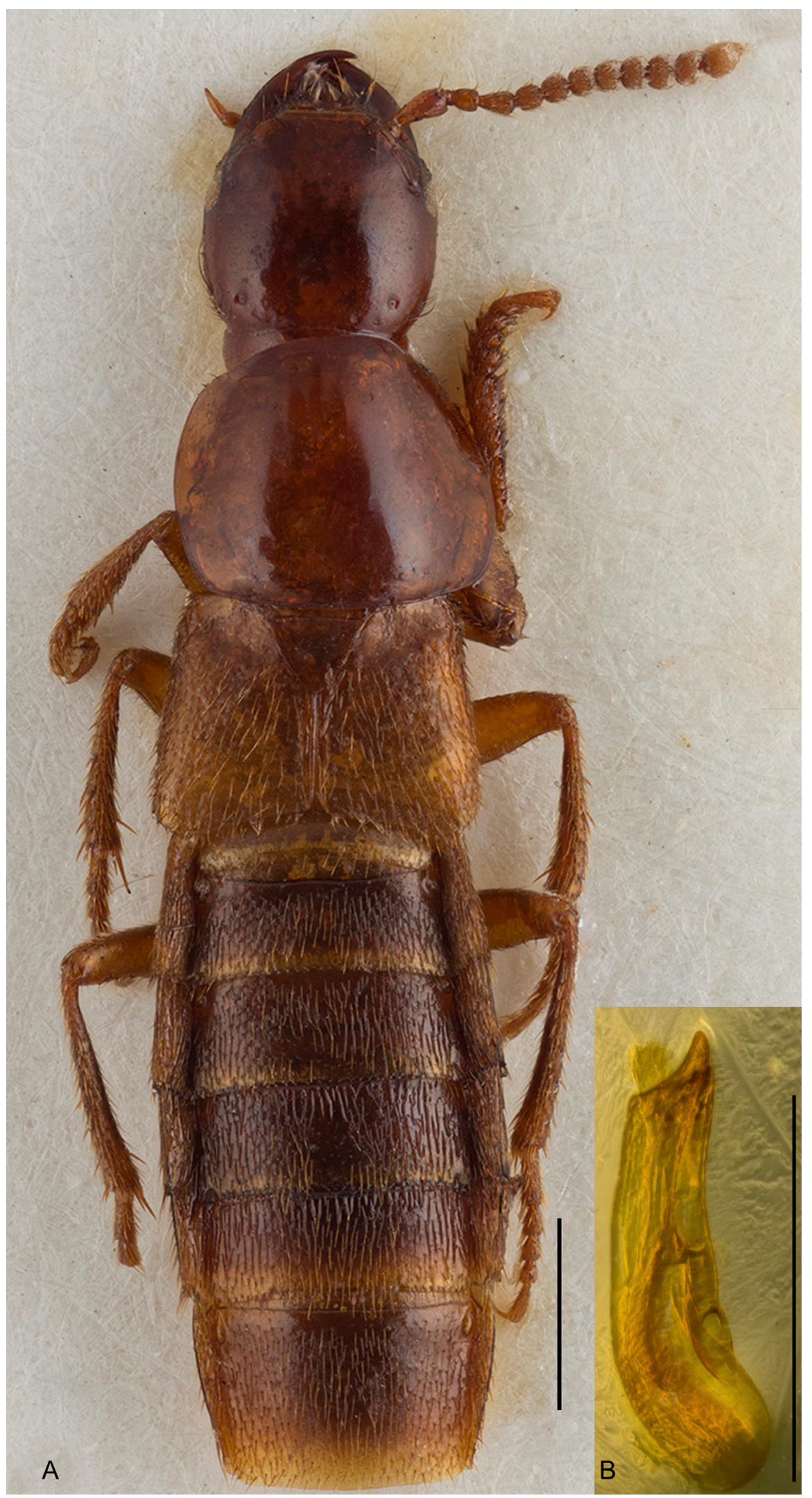

Fig. 2. Lectotype of Quedius mutilatus Eppelsheim, 1888. A. Habitus. B. Permanent preparaion of the aedeagus. Scale bars: $1 \mathrm{~mm}$. 
Some specimens from NMW bear clearly written, but ambiguous geographical labels with 'Turkestan Akinin-Tepe', which we could not interpret in spite of consulting historical literature about I.Y. Akinin's travels in Middle Asia (Jacobson 1902). Based on the structure of the aedeagus, though, these specimens clearly belong to $Q$. mutilatus.

\section{Comparison}

Quedius mutilatus differs from Q. kungeicus sp. nov. by the rhomboid (as opposed to ovoid) apical portion of the paramere and a slight, but distinct incision on its apex (as opposed to indistinct incision; aedeagus in parameral view), as well as the less curved apical portion of the median lobe, with stronger ventral sub-apical tooth (aedeagus in lateral view). From $Q$. kalabi it differs by the more robust and less curved apical portion of the median lobe with its shorter apical part (aedeagus in lateral view) and, usually, by the larger number of sensory peg setae in lateral groups on the paramere. From Q. equus it differs by the less incised apex of the paramere and a distinctly greater number of sensory peg setae in the lateral groups on the paramere.

\section{Notes on the type material}

Quedius mutilatus Eppelsheim, 1888 was described based on two specimens with unclearly recorded collecting localities. Of these, a male comes from 'Fluss. Tamgi' which we interpret as River Tamga in the Karakol Gorge of Terskei Alatau, while a female comes from 'Lake Issyk-Kul', an even less precisely outlined area around a large lake in Kyrgyzstan. Smetana (1998), who designated the male as a lectotype, interpreted the female paralectotype label literally as the Lake Issyk-Kul at ca $1500 \mathrm{~m}$ of elevation and suggested that, unlike the high altitudinal $Q$. kalabi, Q. mutilatus is confined to lower elevations. However, such an interpretation is not confirmed here with new and better georeferenced material.

Before Smetana's lectotype designation and his latest taxonomic treatment of this species, the male syntype was examined by Gridelli (1924), who noted some morphological characters, and by Coiffait (1978), who first illustrated the aedeagus for Q. mutilatus.

It is noteworthy that the paralectotype female of $Q$. mutilatus from 'See Isyk-Kul [Lake Issyk-Kul]' is teneral, slightly smaller than the lectotype and notably smaller than the size range of the non-type specimens. Given its small size and a lack of precise locality information, the species identity of the paralectotype of $Q$. mutilatus remains unclear. Therefore, we list it among other undetermined material of the $Q$. mutilatus group at the end of this paper.

Quedius kalabi Smetana, 1995

Figs 1, 3, 4C-D

Quedius kalabi Smetana, 1995: 77 (original description).

Quedius kalabi - Smetana 1998: 118 (comparison with Q. mutilatus). — Solodovnikov \& Hansen 2016: 7 (distribution).

\section{Material examined}

Type material

KYRGYZSTAN: Holotype, ฮิ, "SU - Tien Shan NE part of Terskey Ala Too [Terskei Alatau] ridge 3000-3600 m" (NMW). 
Additional material

KYRGYZSTAN: 1 ð, 1 , E Terskei Alatau, Teploklyuchenka Village, $2600 \mathrm{~m}\left[42.4400^{\circ} \mathrm{N}, 78.5200^{\circ} \mathrm{E}\right]$, 16 Jun. 1993, S. Ovchinnikov leg. (cSch).

\section{Distribution and bionomics}

Quedius kalabi is known from the three specimens examined here, collected in the Terskei Alatau mountain range at high elevations around 2600-3600 m (Fig. 1). Only two of them bear labels that specify the date and exact collecting locality (16 Jun. 1993, Teploklyuchenka Village). All previously published material for $Q$. kalabi, except the holotype, but including the paratype, was apparently misidentified (see below). Like other species of the Q. mutilatus group, Q. kalabi presumably occurs in talus-associated microhabitats.

\section{Notes on the type material}

Smetana (1995) based his description of $Q$. kalabi on the holotype (male, see above for details) and one paratype (female, for information see the undetermined or ambiguous material at the end of this paper), both from the north-eastern part of Terskei Alatau. The precise geographic origin of the holotype is unknown, while the paratype comes from a locality called Jety Oguz. The aedeagus preparation of the holotype of $Q$. kalabi in Canada balsam allows an examination of its lateral side, not illustrated in Smetana (1995) (Fig. 3B). It confirms our identification of Q. kalabi, which differs from other species of the Q. mutilatus group by its narrower and somewhat curved apical portion of the median lobe of the aedeagus, with a relatively short blade of its subapical tooth (aedeagus in lateral view). In the shape of the apical portion of the paramere and degree of its incision, $Q$. kalabi displays a transition between Q. mutilatus with a less incised paramere bearing more lateral peg setae, and $Q$. equus with a more incised paramere bearing fewer lateral peg setae. The characters indicated by Smetana (1988) in a comparison of $Q$. kalabi with $Q$. mutilatus were based, as revealed here, on non-conspecific males and females of both species. They do not align with the more extensive material examined here. The collecting locality of the paratype of $Q$. kalabi is, in fact, located closer to the distribution area of Q. mutilatus. Except for the holotype, the distributional records of $Q$. kalabi summarized in Solodovnikov \& Hansen (2016) were based on misidentified specimens of Q. mutilatus. The specimens of Q. kalabi from Teploklyuchenka Village, examined here and compared with the holotype, are the first precisely georeferenced material for this species. Based on the shape of aedeagus, three possibly mislabeled specimens from Toksanbai in Dzungarian Alatau seem to belong to Q. kalabi as well (for details see below).

Quedius equus Smetana, 2014

Figs 1, 4G-N

Quedius equus Smetana, 2014: 35 (original description).

Quedius equus - Solodovnikov \& Hansen 2016: 8 (distribution).

Type material (not examined, listed according to Smetana 2014)

Holotype

CHINA: ${ }^{\lambda}$, “CHINA: NW-Xinjiang ca $58 \mathrm{~km}$ WNW Baicheng right trib. of Terek riv. $42^{\circ} 01^{\prime} \mathrm{N}$, $81^{\circ} 15^{\prime} \mathrm{E} / 31.5$. - 2.6.2009 $3500 \mathrm{~m}$ alp. meadows, screes leg. J. Kalab" (NMW).

Paratypes

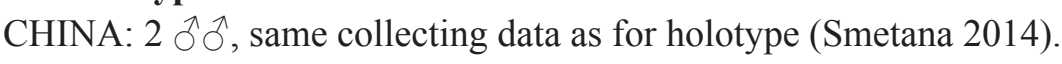




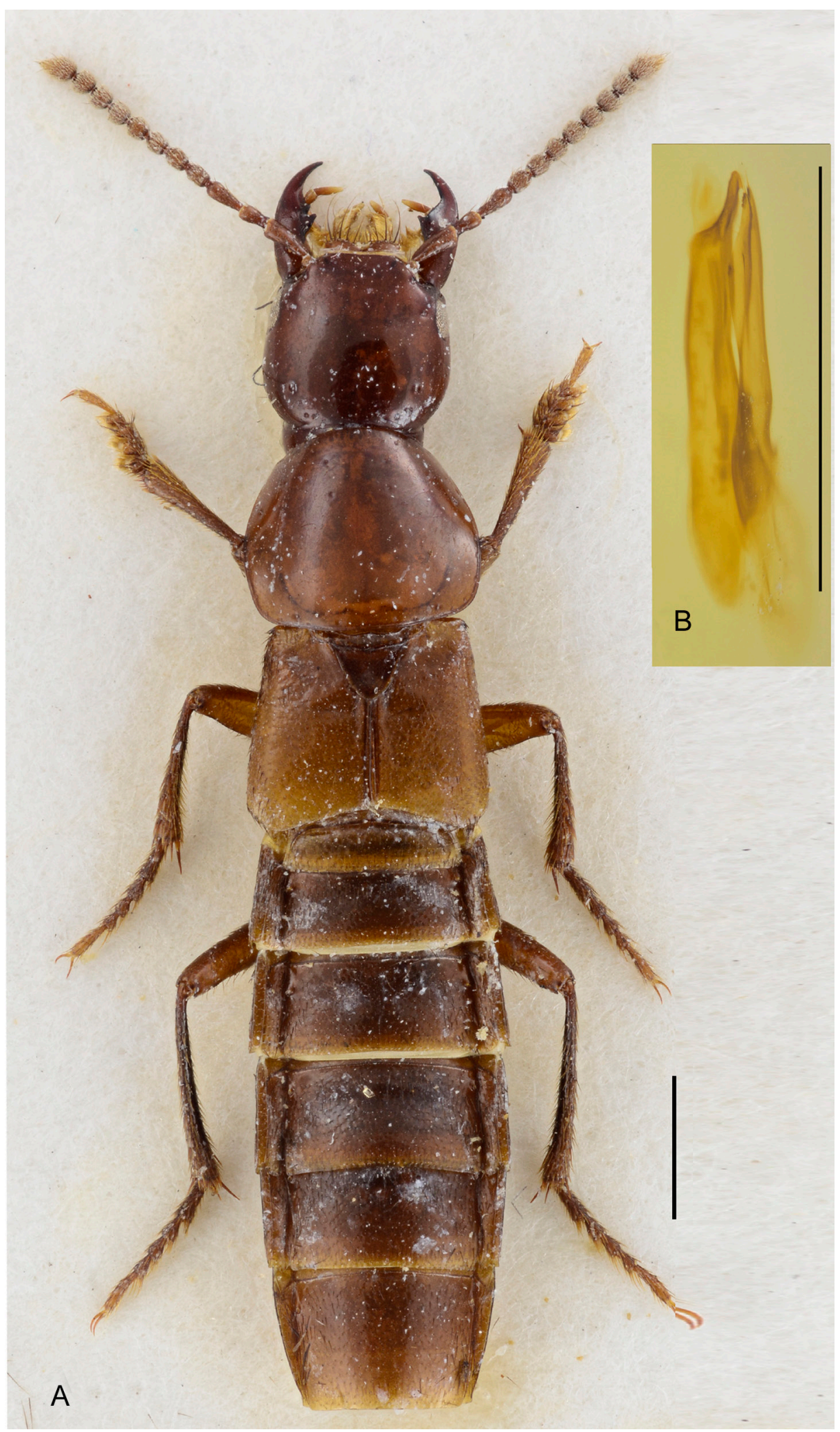

Fig. 3. Holotype of Quedius kalabi Smetana, 1995. A. Habitus. B. Permanent preparation of the aedeagus. Scale bars: $1 \mathrm{~mm}$. 


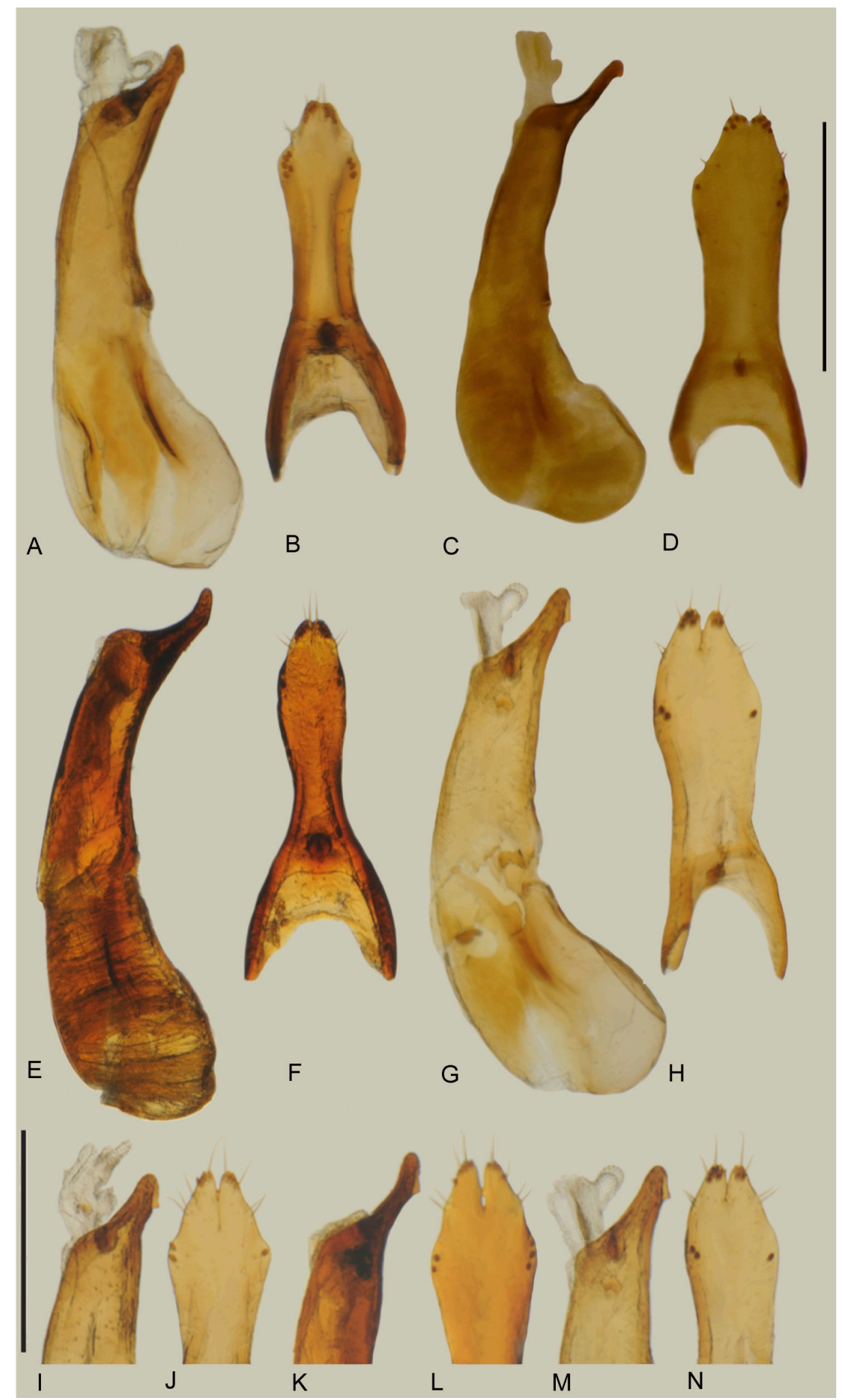

Fig. 4. Aedeagi in the Quedius mutilatus group. A-B. Quedius mutilatus Eppelsheim, 1888. C-D. Quedius kalabi Smetana, 1995. E-F. Quedius kungeicus sp. nov. G-N. Quedius equus Smetana, 2014 (Karkara Valley, Kazakhstan), variability of the structure of the aedeagus. A, C, E, G, I, K, M = median lobe, laterally. B, D, F, H, J, L, N = paramere (dissected from median lobe), underside (side facing median lobe). Scale bars: $1 \mathrm{~mm}$. 


\section{Material examined}

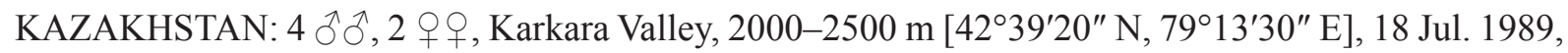

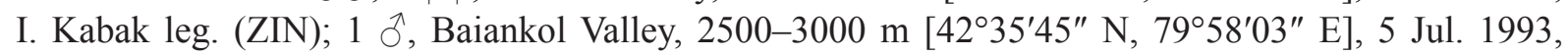

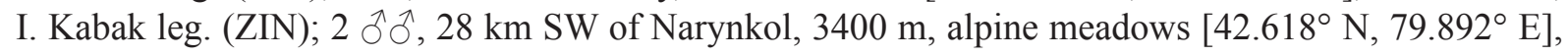
22 Jul. 1984, B. Iskakov leg. (ZIN).

\section{Distribution and bionomics}

Previously, Q. equus was known from the holotype and two paratypes (all males) only, collected together at the type locality in Xinjiang Province in China. New material examined here matches well with the original description and significantly expands the distribution of this species westwards (Fig. 1). All newly studied specimens were collected at high elevations around 2000-3400 m in July. For only two of them does the label specifies alpine meadows as the habitat, which is the same as for the type material.

\section{Comparison}

Quedius equus differs from all other species in the Q. mutilatus group by the deep incision on the apex of the paramere and by fewer (1-3) sensory peg setae in the lateral groups arranged in longitudinal rows.

$$
\begin{aligned}
& \text { Quedius kungeicus sp. nov. } \\
& \text { urn:1sid:zoobank.org:act:FAD25BCE-73E2-4BC0-90EC-5D31FB2F8DBD }
\end{aligned}
$$

Figs 1, 4E-F, 5

\section{Etymology}

The specific epithet 'kungeicus' is a latinized adjective derived from the mountain range where this species was collected.

\section{Material examined}

\section{Holotype}

KAZAKHSTAN: ${ }^{\lambda}$, "Kazakhstan, Kungei Alatau Mountain Ridge, Kurmety valley, 18 km SW from Saty, 2600-2700 m, Picea forest [ca 42 $57^{\prime} 00^{\prime \prime}$ N, 78 ${ }^{\circ} 16^{\prime} 00^{\prime \prime}$ E], 12.VI.1987, leg. I. Kabak” (ZIN).

\section{Description}

Measurements and Ratios. HL: 1.61, HW: 1.48, PL: 1.75, PW: 2.16, EL: 1.64, EW: 2.14, FB: 5.00, HL/ HW: 1.09, PL/PW: 0.81, EL/EW: 0.77.

BoDy. Length: $10 \mathrm{~mm}$; dark brown, hind margins of abdominal tergites slightly paler; appendages of the same coloration as body; body flattened dorso-ventrally. Overall external morphology as in Q. mutilatus, but eyes slightly protruding over lateral contour of head (Fig. $5 \mathrm{~A}$ ).

\section{Male}

Aedeagus (Figs 4 E-F, 5B-D). Apical portion of median lobe (in lateral view) with characteristic 'hump' (shown by arrow in Fig. 5B) more pronounced than in other species of the group and with relatively more elongate apical portion that does not have a pronounced ventral sub-apical tooth; paramere (aedeagus in parameral view) as wide as median lobe, apically ovoid and with hardly visible apical emargination; parameral underside with apical groups of ca 7-8 sensory peg setae on each side of emargination and with two lateral groups of 2-3 peg setae each; parameral apical contour with two pairs of apical setae and two pairs of lateral setae. Internal sac without strong and obvious sclerotized structures.

\section{Female}

Unknown. 


\section{Distribution and bionomics}

Quedius kungeicus sp. nov. is known from the holotype only, which was collected in the Kungei Alatau mountain range at an elevation of around 2600-2700 m in spruce forest. According to Ilya Kabak, who collected the holotype of $Q$. kungeicus sp. nov., it was most likely taken from under stones. This and the habitus of the species suggest an association with talus.

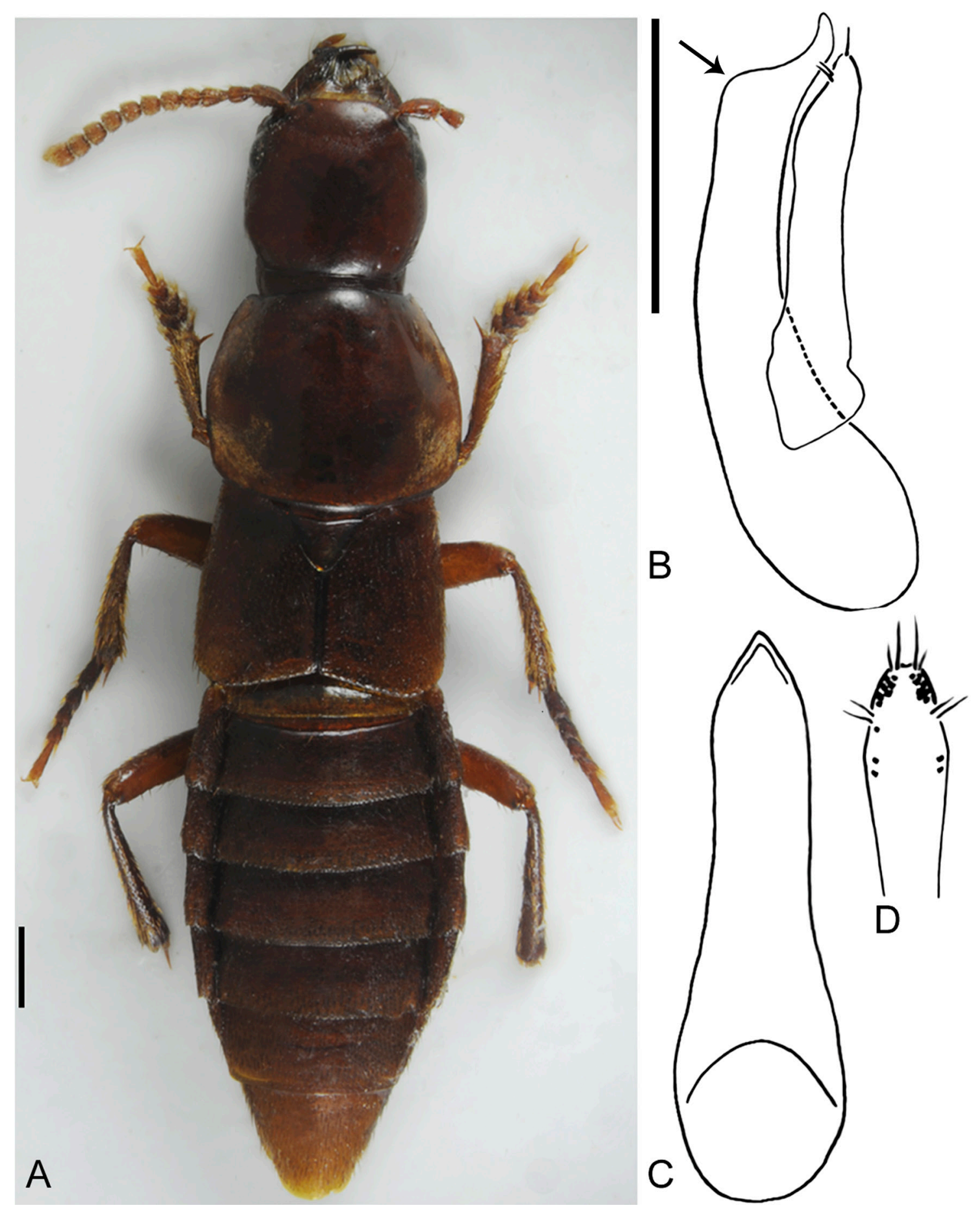

Fig. 5. Quedius kungeicus sp. nov. A. Habitus. B. Aedeagus, laterally. C. Median lobe, in parameral view (paramere detached). D. Paramere, underside (side facing median lobe). Scale bars: $1 \mathrm{~mm}$. 


\section{Comparison}

Quedius kungeicus sp. nov. can be reliably distinguished from all other species of the Q. mutilatus group by the structure of the aedeagus, namely by the ovoid contour of the apical portion of the paramere without a distinct apical incision (aedeagus in parameral view) and by the characteristically curved and longer apical portion of the median lobe that lacks a distinct sub-apical tooth (aedeagus in lateral view).

\section{Quedius spp. from the $Q$. mutilatus group, ambiguously labelled or undetermined material}

The following material could not be identified:

\section{Type material}

KYRGYZSTAN: paralectotype of Q. mutilatus [Kyrgyzstan], +, “mutilatus mihi See Isyk-Kul [Lake Issyk-Kul], Turkestan Akinin [handwritten label]/c.Epplsh. Steind. d [printed label]/TYPUS [red printed label]/ Paralectotype Quedius mutilatus Eppelsheim, 1888 M. Salnitska \& A. Solodovnikov rev. 2016" (NMW); paratype of Q. kalabi [Kyrgyzstan], + , "SU - Tien-Schan Mts, - 3000-3500 m NO part of Terskey Ala Too ridge JETY-OGUZ, - 20 km SW from Przewalsk J. Kalab leg. 23.-30.6.1989'/ QUEDIUS (Microsaurus) sp. nov. ○” (Smetana 1995).

\section{Other material}

KAZAKHSTAN: $2 \hat{\jmath}$ ๙ै, 1 , , Dzungarian Alatau, Toksanbai, upper reaches of Taibuga River $\left[79.7300^{\circ} \mathrm{E}\right.$, 44.9400 N], 11 Jun. 1991, V. Kastcheev leg. (ZIN); 1 q, Central Tien-Shan, Atbashi mountain range, S slope, $3000 \mathrm{~m}\left[75.8800^{\circ} \mathrm{E}, 40.9900^{\circ} \mathrm{N}\right]$, 22 Jul. 1959, Zaslavsky leg. (ZIN); 1 q, 'Turkestan leget Akinin, dedet Faust' (NMW).

For reasons why the paralectotype of $Q$. mutilatus and the paratype of $Q$. kalabi, both females, are likely non-conspecific with the primary type material and cannot be identified, see the comments for the respective species above.

Three specimens from Dzungarian Alatau in ZIN are damaged by dermestids and among them only one of the two males has the aedeagus intact. Based on external morphology, these specimens, collected during the same collecting event, appear conspecific. The structure of the aedeagus preserved in one of them suggests they may be conspecific with $Q$. kalabi or at least represent a very similar taxon. This, in turn, suggests their origin from Terskei Alatau and therefore a case of mislabeling. The presence of the Q. mutilatus group in Dzungarian Alatau, which is outside the known distribution pattern of the group, needs confirmation by other material.

A female specimen from NMW from an indefinite locality recorded as 'Turkestan', and a female from ZIN from the Atbashi mountain range cannot be identified further than being members of the Q. mutilatus group without associated males. It is noteworthy that a female from the Atbashi Range so far represents the southwesternmost and a relatively isolated record of the Q. mutilatus group.

\section{Discussion}

The shared, very uniform external morphology (similar habitus and chaetotaxy), shape and chaetotaxy plan of the aedeagus, as well as biogeographic considerations suggest that the Q. mutilatus group is monophyletic. The phylogenetic affinities of this species group within the subgenus Microsaurus remain unclear. Beetle morphology and the currently known distribution records suggest that the $Q$. mutilatus group consists of hypogean (sensu Solodovnikov \& Hansen 2016) allopatric species. Both assumptions, however, need to be explored and confirmed by robust data, currently unavailable because the group has very rarely been collected. At present, four species of the Q. mutilatus group can be separated 
from each other by clear morphological differences in the structure of the aedeagus only (Fig. 1). The examined material displays notable intraspecific variability, suggesting that species-level taxonomy and the distribution pattern of the $Q$. mutilatus group may appear more complex with denser sampling. In future cases of specimens where morphology and biogeography would not give a clear answer of their species identity, our suggestion would be to downgrade current species of $Q$. mutilatus group to the subspecies level and treat ambiguous material as $Q$. mutilatus ssp. incertae sedis. Such an approach would allow effective documentation of new material until the next level of taxonomic understanding is reached. We would like to stress that our current, exclusively morphology-based species concepts at most set an initial taxonomic frame for a deeper phylogeographic investigation of the Q. mutilatus and similar groups of montane species.

\section{Acknowledgements}

We are obliged to all the people mentioned in the 'Material and methods' section who provided material for examination. In particular, we thank Harald Schillhammer (Vienna) for taking digital images of the type material at NMW under his care. We are very thankful to Alexander Ryvkin and Elena Veselova (Moscow) for their hospitality and support during our visits to study their collection. Alexander Ryvkin, Volker Assing (Hannover) and one anonymous reviewer critically reviewed an earlier version of the manuscript and suggested some improvements. Additionally, we thank Josh Jenkins Shaw (Copenhagen) for the linguistic check of the manuscript. Finally, we express sincere thanks to Fedor Konstantinov (Entomology Department, St. Petersburg University) for the continuous support of the post graduate research by MS. This study was conducted using equipment of the Center for Molecular and Cell Technologies of the Research Park at St. Petersburg State University and sponsored by the 'Inessa's Fund'.

\section{References}

Boháč J. 1988. New and little known Staphylininae (Coleoptera, Staphylinidae). Entomologicheskoe Obozrenie 67: 549-557. [In Russian.]

Coiffait H. 1978. Coléoptères Staphylinidae de la région paléarctique occidentale. III. Sous famille Staphylininae, tribu Quediini; sous famille Paederinae, tribu Pinophilini. Nouvelle Revue d'Entomologie, Supplement 8 (4): 1-364.

Eppelsheim E. 1888. Neue Staphylinen Central-Asiens. Deutsche Entomologische Zeitung 32: 49-67.

Gridelli E. 1924. Studi sul genere Quedius Steph. (Col. Staph.). Secondo contributo. Specie della regione paleartica. Memorie della Società Entomologica Italiana 3 (1): 5-112.

Jacobson G.G. 1902. Vladimir Aleksandrovich Balassoglo. Proceedings of the Russian Entomological Society V: 35. [In Russian.]

Reitter E. 1887. Insecta in itinere Cl. N. Przewalskii in Asia Centrali novisime lecta. VI. Clavicornia, Lamellicornia et Serricornia. Horae Societatis Entomologicae Rossicae 21: 201-234.

Smetana A. 1995. Taxonomic and faunistic contributions to the knowledge of Palearctic Quediina (Coleoptera, Staphylinidae, Staphylinini). Elytra (Tokyo) 23: 77-88.

Smetana A. 1998. Taxonomic and faunistic contributions to the knowledge of Palearctic Quediina (Coleoptera, Staphylinidae, Staphylinini). Part 2. Elytra (Tokyo) 26 (1): 115-128.

Smetana A. 2001. Contributions to the knowledge of the Quediina (Coleoptera, Staphylinidae, Staphylinini) of China. Part 20. Genus Quedius Stephens, 1829. Subgenus Microsaurus Dejean, 1833. Section 12. Elytra (Tokyo) 29 (1): 193-216. 
Smetana A. 2014. Contributions to the knowledge of the Quediina (Coleoptera, Staphylinidae, Staphylinini) of China. Part 44. Genus Quedius Stephens, 1829. Subgenus Microsaurus Dejean, 1833. Section 22. Folia Heyrovskyana, Series A 21 (1-4): 1-39.

Solodovnikov A. \& Hansen A.K. 2016. Review of subterranean Quedius, with description of the first hypogean species from the Russian Far East (Coleoptera: Staphylinidae: Staphylinini). Zootaxa 4170 (3): 475-490. https://doi.org/10.11646/zootaxa.4170.3.3

Manuscript received: 19 June 2017

Manuscript accepted: 11 September 2017

Published on: 6 February 2018

Topic editor: Gavin Broad

Section editor: Max Barclay

Desk editor: Kristiaan Hoedemakers

Printed versions of all papers are also deposited in the libraries of the institutes that are members of the EJT consortium: Muséum national d'Histoire naturelle, Paris, France; Botanic Garden Meise, Belgium; Royal Museum for Central Africa, Tervuren, Belgium; Natural History Museum, London, United Kingdom; Royal Belgian Institute of Natural Sciences, Brussels, Belgium; Natural History Museum of Denmark, Copenhagen, Denmark; Naturalis Biodiversity Center, Leiden, the Netherlands; Museo Nacional de Ciencias Naturales-CSIC, Madrid, Spain; Real Jardín Botánico de Madrid CSIC, Spain. 